\title{
Predictive Score Model of Clinical Outcomes Sepsis in Intensive Care Unit Tertier Referral Hospital of Eastern Indonesia
}

\author{
Metta Octora $^{1,2,3}$ (D) Ni Made Mertaniasih ${ }^{1,2 *}$ (D) Bambang Pujo Semedi ${ }^{4} \mathbb{D}$, Eko Budi Koendhori ${ }^{1,2} \mathbb{D}$ \\ ${ }^{1}$ Department of Medical Microbiology, Faculty of Medicine, University of Airlangga, Surabaya, Indonesia; ${ }^{2}$ Department of \\ Clinical Microbiology, RSUD Dr. Soetomo, Surabaya, Indonesia; ${ }^{3}$ Division of Microbiology, Faculty of Medicine, University of \\ Mataram, Mataram, Indonesia; ${ }^{4}$ Department of Anesthesiology and Reanimation, Faculty of Medicine, University of Airlangga, \\ Surabaya, Indonesia
}

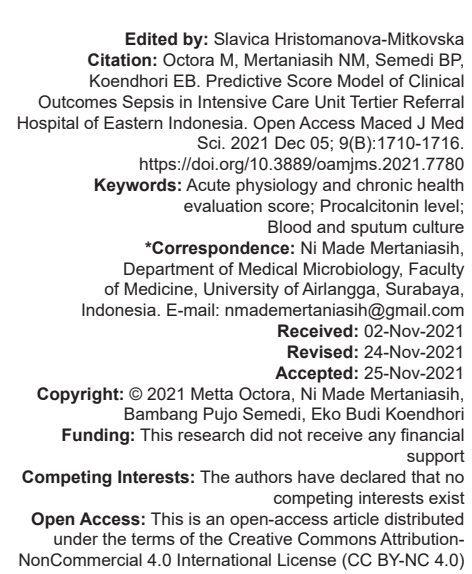

\section{Introduction}

Sepsis is the leading cause of mortality for critically ill patients admitted to the intensive care unit (ICU). Sepsis is a life-threatening organ dysfunction resulting from the host response to infection [1]. The WHO in the Global Report on the Epidemiology and Burden of Sepsis, states that the worldwide incidence of sepsis is 48.9 million and sepsis-related mortality is 11 million, almost $20 \%$ of all global deaths [2]. Data from a systematic review of 1990-2017 states that the hospital mortality rate due to sepsis is estimated to be $27 \%$ and approximately $42 \%$ of patients are admitted to the ICU due to sepsis. The incidence of sepsis and mortality have a regional disparity between the low- and middle-income countries significantly, around $85.0 \%$ of sepsis cases and sepsis-related deaths worldwide [3]. Indonesia is the most populous country in Southeast Asia and the fourth most populous country globally, which has a high incidence of infectious diseases, including sepsis [4].

Prediction of sepsis clinical outcome can be done using a scoring system, so as to determine the appropriate patient management. Sepsis clinical outcome is known to correlate individually with score predictor of Acute Physiology and Chronic Health Evaluation II (APACHE II), blood and sputum culture results, antimicrobial resistance test in blood and sputum cultures, and procalcitonin (PCT) levels [5], [6], [7], [8], [9]. Predictor of APACHE II score has 3 main indicators, namely age, comorbidities, and acute physiological conditions. The indicator of acute 
physiology condition consists of 12 parameters which are given a score of $0-4$. A higher score indicates increased mortality with the maximum score of 71 . A score of 25 indicates a $50 \%$ predicted mortality and a score over 35 indicates an $80 \%$ predicted mortality [9]. Vijay Ganapathy et al. state that the APACHE II score at $24 \mathrm{~h}$ after admission to the ICU was $<24$, so it was estimated that the patient's prognosis was good. Patients with an APACHE II score of 24-27 have a high probability of morbidity and length of stay in the ICU [10]. APACHE II scores have been used for assessing mortality, but this score is not specific to sepsis patients [11].

Sepsis mortality is often associated with bacteremia, which can be detected using the blood culture predictor. Gram-positive bacteria, the main cause of bacteraemia is Staphylococcus aureus. The highest incidence of mortality in relation to tertiary hospitals bloodstream infection is caused by Gram-negative bacilli and $S$. aureus [12]. Antimicrobial resistance is increasing rapidly today is related to mortality in sepsis patients. Study by Malekolkottab et al., states that there is a relation among clinical response and patient outcome caused by multidrug resistance (MDR) against Gram-negative and it was concluded that $58.2 \%$ of patients died due to MDR antibiotics [13]. A study by Sunenshine et al. states that the increased risk of mortality in Acinetobacter baumannii MDR related to carbapenem resistance [14].

Role of sputum culture predictor as a diagnostic tool in hospital-acquired pneumonia (HAP) as well as ventilator acquired pneumonia (VAP) which contribute to the mortality of critically ill patients is still controversial [15]. The Infectious Diseases Society of America guidelines recommend Gram stain and sputum culture to be only performed on severe pneumonia, especially intubated patient in empirical therapy of methicillin-resistant $S$. aureus (MRSA) or Pseudomonas aeruginosa, previously infected with MRSA or $P$. aeruginosa, especially a respiratory tract infection or hospitalized and receiving parenteral antibiotics, whether or not treated for at least the last 90 days [16].

PCT level predictors have been generally recommended for diagnosing the severity of sepsis. A study by Tsangaris et al. (2009) shows that high PCT levels are a marker of poor prognosis [17]. These six predictors are arranged to form a predictive score of sepsis clinical outcomes in critically ill patients in the ICU of a tertiary referral hospital of Eastern Indonesia. So far, microbiological indicators are not used to establish the prognosis of sepsis, but only using clinical and non-microbiological laboratory markers such as liver function, kidney function, etc. This study intends to make a more comprehensive mortality prognostic score.

\section{Methods}

This study aimed to design a predictive score model for sepsis prognosis in the ICU of Dr Soetomo Hospital Indonesia, as a tertiary referral hospital in Eastern Indonesia. An observational retrospective study with non-reactive research conducted in 2017-2020. Ethical clearance was issued by Dr. Sutomo Hospital with no.0321/LOE/301.4.2/II/2021.

This study was using secondary data. APACHE II components consist of 3 main components, namely (1) Acute Physiology Score: $\mathrm{AaDO} 2$ or $\mathrm{PaO} 2$ (for $\mathrm{FiO} 2 \geq 0.5$ or $<0.5$, respectively), body temperature (rectal), mean arterial pressure, blood $\mathrm{pH}$, heart rate, respiratory rate, serum sodium, serum potassium, creatinine (Double point score for acute renal failure), hematocrit, white blood cell count, Glasgow Coma Scale, (2) Age, (3) Chronic disease.

The APACHE score has not been specifically used to assess the mortality prognosis of septic patients but is used to assess the general mortality prognosis. So the researcher intends to use APACHE as a determinant of the model from a clinical and nonmicrobiological laboratory point of view The APACHE scores in this study were obtained from medical record that calculated for each patient admitted to the ICU, so it was already in a score in the medical record.

Blood culture, sputum culture, PCT level, and antimicrobial test data were obtained from medical record (secondary data). Blood and sputum culture, as well as antimicrobial test, were obtained from examination results using the Automated Identification and susceptibility testing system BD Phoenix that recorded in the patient's medical record. So the researcher only collect the data.

The predictors model used to design prognosis was the APACHE II score, blood, and sputum culture results, PCT levels, and antimicrobial resistance test to blood and sputum cultures. Inpatient data obtained from medical record data with clinical outcomes patients while being treated at Dr. Soetomo Hospital. Research subject criteria were 355 subjects with aged 17-65 years diagnosed with sepsis including septic shock. The inpatient data did not accurately excluded from the study. Data were analyzed bivariate and multivariate with logistic regression and receiver operating characteristic (ROC) curves with SPSS 25.

\section{Results}

From a total of 355 subjects, it was found that sepsis-related mortality was $21.7 \%$ while mortality 
due to sepsis shock was $49.6 \%$ with a mean mortality age of 49.71 years, and a significant difference was found between the ages of the subjects surviving and dying ( $p=0.039$ ). Mean APACHE II score of surviving subjects was 15.62 while dying subjects was 23.24 (Table 1). Surviving subjects were mainly dominated by the low and moderate score categories, (34.3\% and $41.2 \%$ ) while dying subjects were dominated by the high moderate and high score categories $(25.3 \%$ and $31.6 \%$ ). The APACHE II score based on the risk of patient mortality found a significant correlation with mortality in sepsis patients $(p=0.000)$.

Table 1: Characteristics of research subjects

\begin{tabular}{lllll}
\hline Parameters & \multicolumn{2}{l}{ Outcome $(\%)$} & Total $(\%)$ & $\mathrm{p}$ \\
\cline { 2 - 3 } & Survive & Death & & \\
\hline $\mathrm{n}=355$ & $102(28.73)$ & $253(71.27)$ & & \\
mean age & 46.92 & 49.71 & & 0.039 \\
Mean APACHE II & 15.62 & 23.24 & & 0.01 \\
Mean PCT & 14.33 & 25.90 & & 0.094 \\
Gender & & & & 0.461 \\
$\quad$ Male & $48(13.5)$ & $130(36.6)$ & $178(50.1)$ & \\
$\quad$ Female & $54(15.2)$ & $123(34.7)$ & $177(49.9)$ & \\
\hline APACHE: Acute physiology and chronic health evaluation, PCT: Procalcitonin. &
\end{tabular}

PCT levels $<0.5 \mathrm{ng} / \mathrm{mL}$ were found the most in the group of surviving subjects (43.1\%). The highest incidence of mortality $(47 \%)$ was experienced by patients who had a PCT level $>10 \mathrm{ng} / \mathrm{mL}$ and there was a significant correlation between PCT levels and sepsis clinical outcome (mortality) $(p=0.000)$ (Table 2).

Table 2: Correlation of predictors and patient outcomes

\begin{tabular}{|c|c|c|c|c|c|}
\hline \multirow[t]{2}{*}{ Predictor } & \multicolumn{2}{|c|}{ Outcome (\%) } & \multirow[t]{2}{*}{$p$} & \multirow[t]{2}{*}{$\mathrm{r}$} & \multirow[t]{2}{*}{ Odds ratio } \\
\hline & Survive & Death & & & \\
\hline \multicolumn{6}{|l|}{$n=355$} \\
\hline \multicolumn{6}{|l|}{ APACHE II scores } \\
\hline Low score 3-10 & $35(34.3)$ & $42(16.6)$ & 0.000 & 0.294 & 3.465 \\
\hline Moderate score 11-20 & $42(41.8)$ & $67(26.5)$ & & & \\
\hline High moderate score $21-30$ & $16(15.7)$ & $64(25.3)$ & & & \\
\hline High score $>30$ & $9(8.8)$ & $80(31.6)$ & & & \\
\hline \multicolumn{6}{|l|}{ Blood culture result } \\
\hline Gram negative bacteria & $7(6.8)$ & $37(14.7)$ & 0.017 & 0.194 & 8.439 \\
\hline Gram positive bacteria & $31(30.5)$ & $87(34.4)$ & & & \\
\hline Polymicrobial & 0 & $5(2)$ & & & \\
\hline Candida spp & 0 & $4(1.6)$ & & & \\
\hline Sterile & $64(62.7)$ & $120(47.4)$ & & & \\
\hline \multicolumn{6}{|l|}{ Sputum culture result } \\
\hline Gram negative bacteria & $55(53.8)$ & $145(57.4)$ & 0.362 & 0.164 & 3.771 \\
\hline Gram positive bacteria & $6(5.9)$ & $12(4.8)$ & & & \\
\hline Polymicrobial & $8(7.8)$ & $18(7.1)$ & & & \\
\hline Candida spp & $1(1)$ & $6(2.4)$ & & & \\
\hline $\begin{array}{l}\text { Normal flora of the respiratory } \\
\text { tract }\end{array}$ & $32(31.4)$ & $72(28.5)$ & & & \\
\hline \multicolumn{6}{|l|}{ AST Blood } \\
\hline Sterile & $64(62.7)$ & $124(49)$ & 0.013 & 0.155 & \\
\hline Sensitive & $33(32.4)$ & $89(35.2)$ & & & \\
\hline MDR & $5(4.9)$ & $40(15.8)$ & & & \\
\hline \multicolumn{6}{|l|}{ AST Sputum } \\
\hline Sterile & $32(31.4)$ & $72(28.5)$ & 0.576 & 0.056 & \\
\hline Sensitive & $18(17.6)$ & $37(14.6)$ & & & \\
\hline MDR & $52(51)$ & $144(56.9)$ & & & \\
\hline \multicolumn{6}{|l|}{ РСT level } \\
\hline Local infection $<0.5$ & $44(43.1)$ & $18(7.1)$ & 0.000 & 0.443 & 6.934 \\
\hline Systemic infection $0.5-<2$ & $26(25.5)$ & $34(13.4)$ & & & \\
\hline Severe infection 2-10 & $17(16.7)$ & $82(32.4)$ & & & \\
\hline Sepsis shock $>10$ & $15(14.7)$ & $119(47)$ & & & \\
\hline
\end{tabular}

Bacteria type of blood culture were dominated by Gram-positive bacteria (33.2\%), while Gram-negative bacteria were only $12.5 \%$. The mortality of most sepsis patients is correlated with Gram-positive (34.4\%), while Gram-negative is only $14.7 \%$. The mortality of sepsis in the ICU of Dr Soetomo Hospital with the highest blood culture results was caused by coagulase-negative Staphylococcus (CoNS) (22.9\%), others were caused by $S$. aureus (4.3\%), Enterobacteriaceae group (8.7\%), A. baumannii (4 \%), Burkholderia cepacia $(0.8 \%)$, $P$. aeruginosa $(0.4 \%)$, polymicrobial infections $(2 \%)$ and Candida spp. (1.6\%). The results show that there is a significant correlation of germs in blood specimens with the outcome of sepsis $(p=0.017)$. The mortality of polymicrobial infection and Candida spp. is $100 \%$ each (Tables 2 and 3).

Table 3: Microbial profile of blood culture of sepsis patients in the ICU

\begin{tabular}{|c|c|c|c|c|}
\hline \multirow[t]{2}{*}{ Blood culture germs } & \multicolumn{2}{|c|}{ Outcome (\%) } & \multirow[t]{2}{*}{ Total } & \multirow[t]{2}{*}{$\mathrm{p} / \mathrm{r}$} \\
\hline & Survive & Death & & \\
\hline \multicolumn{5}{|l|}{$n=355$} \\
\hline Gram negative bacteria & $7(6.8)$ & $37(14.7)$ & $44(12.5)$ & $p=0.017$ \\
\hline Acinetobacter baumanii & $3(2.9)$ & $10(4)$ & $13(3.7)$ & \\
\hline Pseudomonas aeruginosa & 0 & $1(0.4)$ & $1(0.3)$ & $r=0.194$ \\
\hline Enterobacteriaceae & $4(3.9)$ & $22(8.7)$ & $26(7.3)$ & \\
\hline Burkholderia cepacia & 0 & $2(0.8)$ & $2(0.6)$ & \\
\hline Other Gram negative bacteria & 0 & $2(0.8)$ & $2(0.6)$ & \\
\hline Gram positive bacteria & $31(30.5)$ & $87(34.4)$ & $118(33.2)$ & \\
\hline Staphylococcus aureus & $1(1)$ & $11(4.3)$ & $12(3.4)$ & \\
\hline CONS & $28(27.5)$ & $58(22.9)$ & $86(24.2)$ & \\
\hline Enterococcus spp & $1(1)$ & $9(3.6)$ & $10(2.8)$ & \\
\hline Other Gram positive bacteria & $1(1)$ & $9(3.6)$ & $10(2.8)$ & \\
\hline Polymicrobial & 0 & $5(2)$ & $5(1.4)$ & \\
\hline Candida spp & 0 & $4(1.6)$ & $4(1.1)$ & \\
\hline Sterile & $64(62.7)$ & $120(47.4)$ & $184(51.8)$ & \\
\hline
\end{tabular}

The mortality of sepsis in the ICU of Dr Soetomo Hospital with the most sputum cultures of Gram-negative bacteria $(57.4 \%)$ is dominated by A. baumannii (22.1\%), Enterobacteriaceae group $(20.6 \%), P$. aeruginosa (11.1\%), and S. aureus $(22.9 \%)$ (Table 4). There is no significant correlation of bacteria in sputum specimens with the outcome of sepsis ( $p=0.362$ ). Omnibus test showed that independent variables consist of APACHE II score, PCT level, blood, and sputum culture result significantly simultaneously influence clinical outcome $(p=0.000)$.

Table 4: Microbial profile of sputum cultures of sepsis patients in the ICU

\begin{tabular}{|c|c|c|c|c|}
\hline \multirow[t]{2}{*}{ Sputum culture germ } & \multicolumn{2}{|c|}{ Outcome $(\%)$} & \multirow[t]{2}{*}{ Total $(\%)$} & \multirow[t]{2}{*}{$\mathrm{p} / \mathrm{r}$} \\
\hline & Survive & Die & & \\
\hline \multicolumn{5}{|l|}{$n=355$} \\
\hline Gram negative bacteria & $55(53.8)$ & $145(57.4)$ & $200(56.3)$ & $p=0.362$ \\
\hline Acinetobacter baumanii & $13(12.7)$ & $56(22.1)$ & $69(19.4)$ & \\
\hline Pseudomonas aeruginosa & 15 (14.7) & $28(11.1)$ & $43(12.1)$ & $r=0.164$ \\
\hline Enterobacteriaceae & $24(23.5)$ & $52(20.6)$ & 76 (21.4) & \\
\hline Other Gram negative bacteria & $3(2.9)$ & $9(3.6)$ & $12(3.4)$ & \\
\hline Gram positive bacteria & $6(5.9)$ & $12(4.8)$ & $18(5.1)$ & \\
\hline Staphylococcus aureus & $2(2)$ & $5(2)$ & $7(2)$ & \\
\hline Enterococcus spp. & $4(3.9)$ & $3(1.2)$ & $7(2)$ & \\
\hline Other Gram positive bacteria & 0 & $4(1.6)$ & $4(1.1)$ & \\
\hline Polymicrobial & $8(7.8)$ & $18(7.1)$ & $26(7.3)$ & \\
\hline Candida spp. & $1(1)$ & $6(2.4)$ & $7(2)$ & \\
\hline Normal flora of the respiratory tract & $32(31.4)$ & $72(28.5)$ & $104(29.3)$ & \\
\hline
\end{tabular}

The antimicrobial susceptibility test table is not shown because its results of the model test showed no significant results in the formation of the mortality prognostic score, so it was not included in the model.

The results of the antimicrobial resistance test in blood cultures obtain significant correlation with sepsis $(p=0.013)$ but in sputum culture outcomes obtain no significant correlation with the score of $p=0.567$. Omnibus test showed that independent variables consisting of results of the antimicrobial resistance test in blood cultures and sputum have been eliminated in iteration steps of logistic regression. 
The equation of the predictive score model for sepsis clinical outcome in the ICU of Dr Soetomo Hospital of Eastern Indonesia is as follows with a cutoff of 3 .

Predictive score $=1.61^{*} \mathrm{PCT}$ level $+1.35^{*}$ blood culture result $+1.1^{*}$ sputum culture result $+1^{\star} \mathrm{APACHE}$ score

The mortality outcome can be predicted using sepsis predictive score. The most predictor score contribute on mortality in sepsis patients, namely, PCT levels (the highest), blood culture results, sputum culture results, and APACHE II scores (the lowest). If a predictive score for the sepsis clinical outcome is obtained $\geq 3$ then the predicted subject will die, while if the score obtained is $<3$ the predicted subject will survive (Table 5 ).

Table 5: Prognostic predictive score for sepsis patients

\begin{tabular}{lc}
\hline Variable & Score \\
\hline Procalcitonin levels & 0 \\
$2 \mathrm{ng} / \mathrm{mL}$ & 2 \\
$>2 \mathrm{ng} / \mathrm{mL}$ & \\
APACHE II scores & 0 \\
20 & 1 \\
$>20$ & \\
Sputum culture interpretation & 0 \\
$\quad$ Sterile/contaminant & 1 \\
$\quad$ rrue pathogen & 0 \\
Blood culture interpretation & 1 \\
$\quad$ Sterile/contaminant & \\
$\quad$ True pathogen & \\
Total & \\
\hline APACHE: Acute physiology and chronic health evaluation. &
\end{tabular}

The results of the probability of the score and the outcome of mortality show that the higher the score, the higher the probability of mortality, even at a score of 5 , the probability of death is above $99 \%$ (Figure 1) The equation of the clinical outcome predictive score model for sepsis with ROC analysis can be determined the best cut-off point score for predicting the incidence of sepsis mortality outcome. ROC analysis based on equation model obtained area under curve $0.859(p=0.000)$ which indicates that the equation is statistically significant in predicting sepsis clinical outcome (Figure 2).

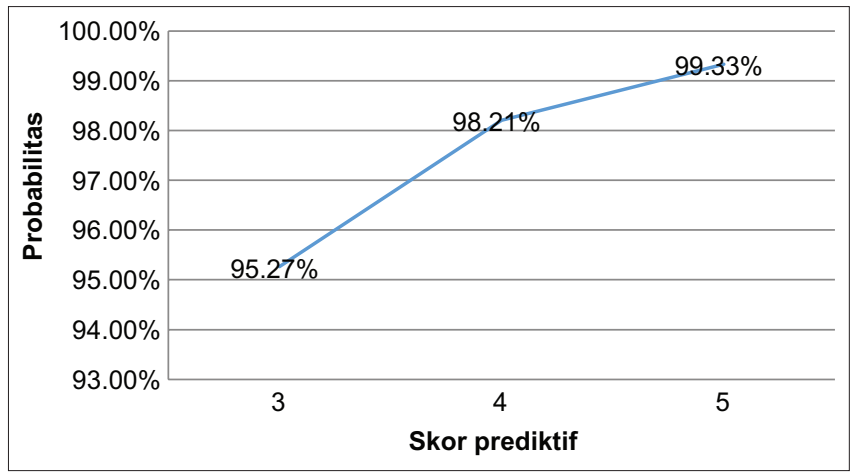

Figure 1: Probability of predictive score and died outcome

\section{Discussion}

Sepsis-related mortality of patient critically ill in the ICU of Dr. Soetomo Hospital was $21.7 \%$ while mortality in patients with sepsis shock was $49.6 \%$. This mortality prevalence is supported by several sepsis studies in various cities in Indonesia [18]. Vincent et al. state that the mortality of patients with severe sepsis in intensive care reached $32.2 \%$ and increased to $54.1 \%$ in sepsis shock [19]. ICU sepsis mortality rate references like Dr. Kandou Hospital, Manado, and Dr Sardjito Hospital, Yogyakarta respectively by $65.7 \%$ and $56.83 \%$ [20], [21].

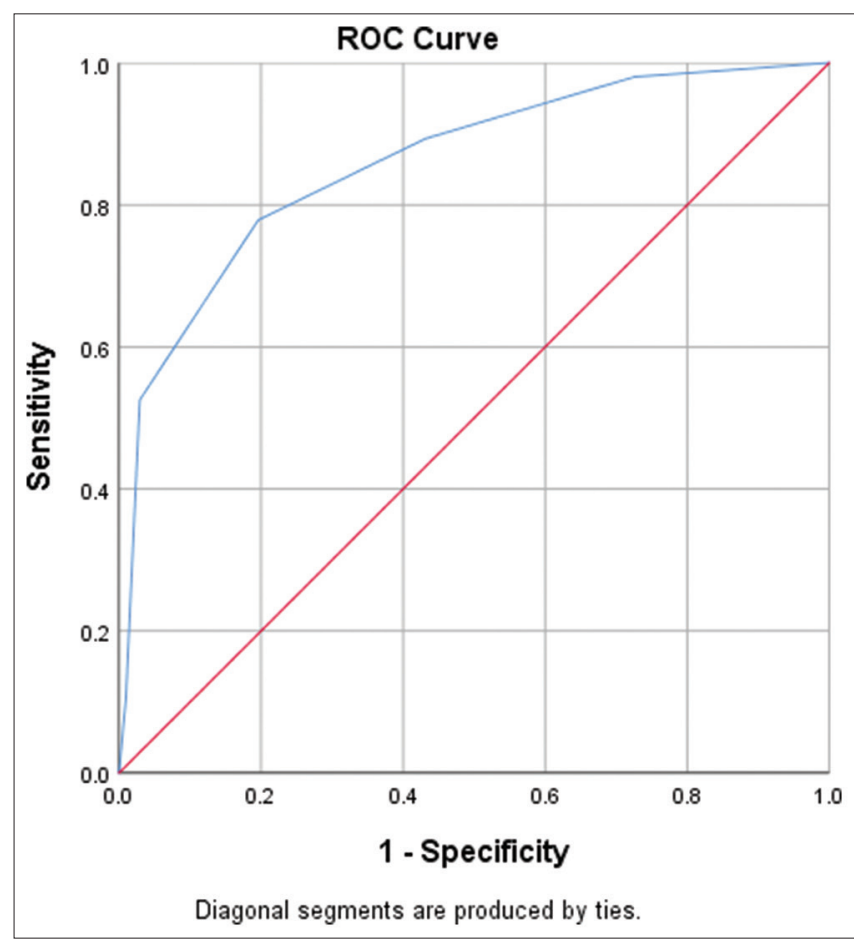

Figure 2: Receiver operating characteristic curve of predictive score for sepsis prognosis

Study by Tanriover et al., in a tertiary referral hospital in Turkey showed that the incidence of sepsis mortality was $87.3 \%$. The mortality rate was $92.2 \%$ with at least one organ dysfunction (respiratory, renal, hepatic, or hematological organ) compared to $44.4 \%$ without any organ dysfunction [22]. Severe sepsis deaths in Poland and Russia reported each $55 \%$ and $54 \%$ [23], [24].

High mortality of sepsis patient influenced by immunosuppressed conditions and the incidence of MDR when treated at ICU. Number of MDR incident is high, especially patients who have been hospitalized for a long time before being referred from a primary or secondary hospital, thereby increasing patient mortality in tertiary hospitals. Most of the patients in the ICU also using mechanical ventilation which was independently significantly correlated with mortality [25]. Multiple critical conditions also likely contributed to the high incident of nosocomial infection and mortality. Microbiological diagnosis of Enterobacteriaceae group is almost always considered as a causative agent of nosocomial infections. The positivity of blood culture in only one location is often underestimated existence possible role of fastidious pathogens due to increased 
usage of intravascular catheter and device-related blood infection including prosthetics [26].

The predictor of PCT level has the greatest contribution in forming the prognostic score. From randomized control trial of PCT in the Netherlands, it was found that the use of PCT-guided antibiotics therapy significantly reduced the mortality of sepsis patients at 28 days to 1 year [27].

The spectrum of microorganisms that cause bacteremia is currently shifting from Gram-negative to Gram-positive bacteria, apart from fungi which are emerging as important pathogens. Gram-negative bacteria currently play an important role in tertiary referral hospitals [28]. Several studies suggest that blood culture results are generally dominated by $65.9 \%$ by Gram-negative bacteria. Klebsiella sp. Escherichia coli and Enterobacter sp. are the main Gram-negative pathogens causing bacteremia [22]. Pathogenic profiles that cause bacteremia are differentiated from community- and hospital-acquired bacteremia. The incidence of community-acquired bacteremia was dominated by Gram-positive bacteria (56.2\%), while pathogens acquired in the hospital were dominated by Gram-negative bacteria $(80 \%)$. Severe sepsis is dominated by Gram-negative bacteria with high MDR rates and patients are managed with broad-spectrum antibiotics [28].

Sohail et al., state that the most common bacteria found in patients admitted to the ICU of tertiary referral hospitals were S. aureus (36.38\%), E. coli $(18.28 \%)$, and MRSA (7.0\%). Other bacteria include Enterococcus faecalis, Salmonella typhi, Pseudomonas sp, and Candida spp [29]. The highest death rate for tertiary hospitals in Vietnam-related bloodstream infection is caused by the Enterobacteriaceae group, which is $34.7 \%(61.6 \%$ of the mortality rate in the hospital), Klebsiella pneumoniae (37.4\%) and E. coli $(37.1 \%)$ as well as S. aureus (48\%) [12]. The pathogenic profile of sepsis in several studies has always been related to the focus of infection, severity of infection, antibiotics resistance, comorbidities such as immunodeficiency, chronic kidney, and liver disease, besides socioeconomic, climatic, and geographic factors as well as increased life expectancy [30].

Role of sputum culture as a diagnostic tool HAP as well as VAP on mortality in critically ill patients still need to be investigated further. A prospective study on 2554 cases of adult HAP or VAP in 10 Asian countries (2008-2009), Acinetobacter spp. was found to be the most common organism, accounting for $36.5 \%$ of all pneumonias [31]. This is in accordance with the results found in the ICU of Dr. Soetomo Hospital, that $A$. baumannii as the second most common cause of sepsis after the Enterobacteriaceae group with a total positive sputum culture of $19.4 \%$, and a mortality of $22.1 \%$.

Several decades, sputum culture for diagnosing pneumonia are debated, because its reliability of microbiological diagnosis is low (low sensitivity and specificity). Most sputum specimens are improperly collected and contain oropharyngeal or upper respiratory tract secretions. A prospective study of the diagnostic value of sputum culture in acute pneumonia with transtracheal aspiration and/or bronchial aspiration techniques did not provide a better diagnostic value than sputum culture alone, even though the sputum collected was of good quality [15].

Only one-third of the pneumonia-causing organisms were found from good quality sputum. The results of positive sputum cultures in the good quality and poor quality groups according to the severity of pneumonia using the PORT system showed no significant difference [32]. Delays in processing sputum specimens for more than 24 hours are associated with increased isolation of Candida spp. [18] Recovery of sputum culture microorganisms is very low due to factors such as sputum processing and collection and prior antibiotic therapy, which may decrease diagnostic results [15]. Sputum culture values decreased with prehospitalization of antibiotics, but in a large number of samples, Streptococcus pneumoniae and Haemophilus influenzae could be isolated even though the patient had taken antibiotics prior to sputum culture. This study also shows that the correlation between sputum culture and mortality is not significant and the correlation of resistance test in sputum culture is found to be not significant to mortality [32].

Antimicrobial resistance is natural phenomenon in microbes (bacteria/fungi) that happens continuously. The crisis of antibiotic resistance occurs because antibiotics tend to lose their efficacy due to the spread of resistance among pathogenic bacteria. This resistance is mainly due to the high use of antibiotics in hospitals, especially for critically ill patients. Growing elderly population indirectly related to the increase in the use of antibiotics due to an increase in the number of patients hospitalized. This makes patients more exposed to the hospital environment, causing an increase in the number of nosocomial infections. Tertiary referral hospital, tend to accept patient case of heavy reference or failed therapy so that result in high rates of resistance and case fatality rates which are also exacerbated by MDR nosocomial infections [33]. Pea and Viale (2009), state that the pharmacokinetic and pharmacodynamic properties of antimicrobials are associated with changes in clearance and volume of distribution that are common in critically ill patients, so that it could affect drug concentration at the site of infection and subsequently affects antimicrobial resistance [34]. Antibiotic resistance is major determinants of clinical unresponsiveness to treatment and rapid progression of sepsis and septic shock incident. Sepsis due to MDRO infection carries a higher risk of in-hospital mortality. Antibiotics resistance mostly happens in gram-negative infections. Gramnegative bacterial infection in pneumonia often causes 
respiratory failure, acute respiratory distress syndrome (ARDS), sepsis, and septic shock [35].

Lung dysfunction in the form of ARDS and kidney failure are multi-organ dysfunction phenomenon that related with high sepsis mortality prognosis [22].

\section{Conclusion}

It is found that the APACHE II score, blood culture result, sputum culture result, and PCT levels are significantly correlated with the clinical outcome of sepsis patients. Antimicrobial resistance test results in blood cultures dan sputum culture are not significantly correlated with sepsis outcomes. Predictive score model of sepsis clinical outcomes resulted is as follows:

Predictive score $=1.61^{*} \mathrm{PCT}$ level $+1.35^{*}$ blood culture result $+1.1^{*}$ sputum culture result $+1{ }^{*} \mathrm{APACHE}$ score

APACHE II score >20, PCT level $>2 \mathrm{ng} / \mathrm{dL}$, interpretation of blood culture as true pathogen, and interpretation of sputum culture as true pathogen is an independent risk factor that simultaneously affects the mortality of sepsis patients with a cutoff value of 3 . If the predictive score for sepsis prognosis is more than or equal to 3 , the patient will die, while for a score of $<3$, the patient will survive.

The bacterial profile of blood cultures is predominately Gram-positive (34.4\%), consisting of CoNS $(22.9 \%)$, and S. aureus $(4.3 \%)$, whereas Sputum culture is predominantly Gram-negative, i.e., A. baumannii (22.1\%), Enterobacteriaceae group (20.6\%), P. aeruginosa (11.1\%), which often lead to MDR, causing a vicious cycle in the management of sepsis.

The implications of this model can be used to assess the mortality prognosis of sepsis patients at Dr. Soetomo Hospital in Surabaya, Indonesia but it still needs to be developed further by conducting a multicenter study in a wider area, so that it can be used to determine the management of sepsis management, whether it is more aggressive or not. This is very helpful in overcoming the limited resources in hospitals, especially in developing countries.

\section{Ethics Approval}

Ethical clearance was issued by $\mathrm{Dr}$. Sutomo Hospital with no.0321/LOE/301.4.2/II/2021.

\section{References}

1. Singer M, Deutschman CS, Seymour CW, Shankar-Hari M, Annane D, Bauer M, et al. The third international consensus definitions for sepsis and septic shock (Sepsis-3). JAMA. 2016;315(8):801-10. https://doi.org/10.1001/jama. 2016.0287 PMid:26903338

2. World Health Organization. Global Report on the Epidemiology and Burden of Sepsis in Current Evidence, Identifying Gaps and Future Directions. Geneva: World Health Organization; 2018.

3. Rudd KE, Johnson SC, Agesa KM, Shackelford KA, Tsoi D, Kievlan DR. Global, regional, and national sepsis incidence and mortality, 1990-2017: Analysis for the global burden of disease study. Lancet (London, England). 2020;395(10219):200-11. https://doi.org/10.1016/S0140-6736(19)32989-7

PMid:31954465

4. World Bank. The World Bank, Population Total. Washington, DC: World Bank; 2018. Available from: Available from: https:// data.worldbank.org/indicator/sp.pop.totl?most_recent_value desc=true. [Last accessed on 2021Aug 17].

5. Suljagić $\mathrm{V}$, Cobeljić M, Janković $\mathrm{S}$, Mirović $\mathrm{V}$, Marković-Denić $\mathrm{L}$, Romić $\mathrm{P}$, et al. Nosocomial bloodstream infections in ICU and non-ICU patients. Am J Infect Control. 2005;33(6):333-40. https://doi.org/10.1016/j.ajic.2005.03.010 PMid:16061139

6. Jensen JU, Heslet L, Jensen TH, Espersen K, Steffensen $P$, Tvede $M$. Procalcitonin increase in early identification of critically ill patients at high risk of mortality. Crit Care Med. 2006;34(10):2596-602. https://doi.org/10.1097/01. CCM.0000239116.01855.61

PMid: 16915118

7. Brusselaers $N$, Vogelaers $D$, Blot $S$. The rising problem of antimicrobial resistance in the intensive care unit. Ann Intensive Care. 2011;1:47. https://doi.org/10.1186/2110-5820-1-47 PMid:22112929

8. Prashanth HV, Saldanha RM, Shenoy S, Baliga S. Predictors of mortality in adult sepsis. Int J Biol Med Res. 2011;2(4):856-61.

9. Knaus WA, Wagner DP, Draper EA. The APACHE III prognostic system. Risk prediction hospital mortality for critically ill hospitalized adults. Chest. 1991;100(6):1619-36. https://doi. org/10.1378/chest.100.6.1619 PMid:1959406

10. VijayGanapathy S, Karthikeyan VS, Sreenivas J, Mallya A, Ramaiah K. Validation of APACHE II scoring system at 24 hours after admission as a prognostic tool in urosepsis: A prospective observational study. Investig Clin Urol. 2017;58(6):453-9. https://doi.org/10.4111/icu.2017.58.6.453 PMid:29124246

11. Bouch DC, Thompson JP. Severity scoring systems in the critically ill. Continuing education in Anaesth. Crit Care Pain J. 2008;8(5):181-8.

12. Dat $\mathrm{V}, \mathrm{Vu}$ HN, Nguyen The H, Nguyen HT, Hoang LB, Tien Viet DV, et al. Bacterial bloodstream infections in a tertiary infectious diseases hospital in Northern Vietnam: Aetiology, drug resistance, and treatment outcome. BMC Infect Dis.20017;17:493. https://doi.org/10.1186/s12879-017-2582-7 PMid:28701159

13. Malekolkottab M, Shojaei L, Khalili H, dan Doomanlou M. Clinical response and outcome in patients with multidrug resistant gram-negative infections. J Res Pharm Pract. 2017;6(1):44-51. https://doi.org/10.4103/2279-042X.200990

PMid:28331866 
14. Sunenshine RH, Wright MO, Maragakis LL, Harris AD, Song $X$, Hebden $\mathrm{J}$, et al. Multidrug-resistant Acinetobacter infection mortality rate and length of hospitalization. Emerg Infect Dis. 2007;13(1):97-103. https://doi.org/10.3201/eid1301.060716 PMid: 17370521

15. Cordero E, Pachon J, Rivero A, Girón-González JA, GómezMateos J, Merino MD, et al. Usefulness of sputum culture for diagnosis of bacterial pneumonia in HIV infected patients. Eur J Clin Microbiol Infect Dis. 2002;21(5):362-7. https://doi. org/10.1007/s10096-002-0729-x

PMid:12072920

16. Metlay JP, Waterer GW, Long AC, Anzueto A, Brozek J, Crothers $\mathrm{K}$, et al. Diagnosis and treatment of adults with community-acquired pneumonia. An official clinical practice guideline of the American thoracic society and infectious diseases society of America. Am J Respir Crit Care Med. 2019;200:e45-67. https://doi.org/10.1164/rccm.201908-1581ST PMid:31573350

17. Tsangaris I, Plachouras D, Kavatha D, Gourgoulis GM, Tsantes A, Kopterides $\mathrm{P}$, et al. Diagnostic and prognostic value of procalcitonin among febrile critically ill patients with prolonged ICU stay. BMC Infect Dis. 2009;9:213. https://doi. org/10.1186/1471-2334-9-213

PMid:20028533

18. Dewi R. Sepsis Pada Anak: Pola Kuman dan Uji Kepekaan. Indonesia: Majalah Kedokteran Indonesia; 2011. p. 101-6.

19. Vincent JL, de Mendonca A, Cantraine F, Moreno R, Takala J, Suter PM. Use of the SOFA score to assess the incidence of organ dysfunction/failure in intensive care units: Results of a multicenter, prospective study. Working group on "sepsisrelated problems" of the European Society of intensive care medicine. Crit Care Med. 2006;26(11):1793-800. https://doi. org/10.1097/00003246-199811000-00016

\section{PMid:9824069}

20. Tambajong RN, Lalenoh DC, Kumaat L. Profil penderita sepsis di ICU RSUP Prof. Dr. R. D. Kandou Manado periode Desember 2014 November 2015. J E-Clin. 2016;4(1):452-7.

21. Widodo U. Profil Pasien Yang Didiagnosis sepsis di Bangsal Penyakit Dalam RS Dr Sardjito Tahun. Jogjakarta: Universitas Gadjah Mada; 2008.

22. Tanriover MD, Guven GS, Sen D, Unal S, Uzun O. Epidemiology and outcome of sepsis in a tertiary-care hospital in a developing country. Epidemiol Infect. 2006;134(2):315-22. https://doi. org/10.1017/S0950268805004978

PMid:16490136

23. Kubler A, Durek G, Zamirowska A, Duszyńska W, Pałysińska B, Gaszyński W, et al. Severe sepsis in Poland: Results of internet surveillance of 1043 cases. Med Sci Monit. 2004;10(11):635-41. PMid:15507856

24. Busund R, Koukline V, Utrobin U, Nedashkovsky E. Plasmapheresis in severe sepsis and septic shock: A prospective, randomised, controlled trial. Intensive Care Med. 2002;28(10):1434-9. https://doi.org/10.1007/ s00134-002-1410-7

PMid:12373468
25. Lundberg JS, Perl TM, Wiblin T, Costigan MD, Dawson J, Nettleman MD, et al. Septic shock: An analysis of outcomes for patients with onset on hospital wards versus intensive care units. Crit Care Med. 1988;26(6):1020-4. https://doi. org/10.1097/00003246-199806000-00019 PMid:9635649

26. Lee A, Mirrett S, Reller LB, Weinstein MP. Detection of bloodstream infectionsin adults: How many blood cultures are needed? J Clin Microbiol. 2007;45(11):3546-8. https://doi. org/10.1128/JCM.01555-07 PMid: 17881544

27. de Jong E, van Oers JA, Beishuizen A. Efficacy and safety of procalcitonin guidance in reducing the duration of antibiotic treatment in critically ill patients: A randomised, controlled, open-label trial. Lancet Infect Dis. 2016;16(7):819-27. https:// doi.org/10.1016/S1473-3099(16)00053-0 PMid:26947523

28. Velasco E, Byington R, Martins CS, Schirmer M, Dias LC, Goncalves VM. Bloodstream infection surveillance in a cancer centre: A prospective look at clinical microbiology aspects. Clin Microbiol Infect. 2004;10(6):542-9. https://doi. org/10.1111/j.1469-0691.2004.00874.x

PMid: 15191383

29. Sohail M, Sultana Q, Rasool K, Sarwar S, Basit A, Khalid M. Bacteremia prediction by inflammatory factors and recent trend in drug resistance of bacteria isolated from blood stream infection. J Inf Mol Biol. 2015;3:75-80. https://doi.org/10.14737/ journal.jimb/2015/3.3.75.807.

30. Mayr FB, Yende S, Angus DC. Epidemiology of severe sepsis. Virulence. 2014;5(1):4-11. https://doi.org/10.4161/viru.27372 PMid:24335434

31. Chung DR, Song JH, Kim SH, Thamlikitkul V, Huang SG, Wang $\mathrm{H}$. High prevalence of multidrug-resistant nonfermenters in hospital-acquired pneumonia in Asia. Am J Respir Crit Care Med. 2011;184(12):1409-17. https://doi.org/10.1164/ rccm.201102-03490C

PMid:21920919

32. Shariatzadeh MR, Marrie T. Does sputum culture affect the management and/or outcome of community-acquired pneumonia? Eastern Mediterr Health J. 2009;15(4):792-9. PMid:20187530

33. Luan Y, Sun Y, Duan S, Zhao P, Bao Z. Pathogenic bacterial profile and drug resistance analysis of community acquired pneumonia in older outpatients with fever. J Int Med Res. 2018;46(11):4596604. https://doi.org/10.1177/0300060518786915 PMid:30027805

34. Pea F, Viale P. Bench-to-bedside review: Appropriate antibiotic therapy in severe sepsis and septic shock does the dose matter? Crit Care. 2009;13:214. https://doi.org/10.1186/cc7774 PMid:19519961

35. Cillóniz C, Dominedò C, Torres A. Multidrug resistant gram negative bacteria in community acquired pneumonia. Crit Care. 2019;23(1):79. https://doi.org/10.1186/s13054-019-2371-3 PMid:30850010 